\title{
Professores sabem o que é bullying? Um tema para a formação docente
}

\author{
Elizângela Napoleão da Silva \\ Universidade Federal de Pernambuco - PE \\ Ester Calland de S. Rosa \\ Universidade Federal de Pernambuco - PE
}

\begin{abstract}
Resumo
A pesquisa, de cunho qualitativo, abordou o bullying na formação de professores, tendo como objetivo refletir a respeito das concepções sobre o fenômeno e do que eles consideram serem formas eficazes de intervenção diante dos casos ocorridos em escolas públicas do ensino fundamental, e ainda sobre as demandas para a formação docente. Foram entrevistados seis professores em uma escola municipal do Recife e seis licenciandos da Universidade Federal de Pernambuco. Como resultado, identificamos que os participantes tiveram dificuldade em definir o bullying e de caracterizar sua abrangência na escola. Consideram o tema relevante, embora apontem que está pouco presente nos cursos de formação. Quanto à intervenção, propõem o diálogo e o envolvimento de pais e de autoridades públicas. Conclui-se que o bullying é reconhecido como problema concernente às escolas e aos professores, porém não se constitui num tópico de estudo sistemático na formação de licenciados.
\end{abstract}

Palavras-chaves: Bullying, formação de professores, ensino fundamental.

\section{Do teachers know what is bullying? A teacher training issue}

\begin{abstract}
This qualitative research focused on how teacher education approaches bullying and aimed to identify what teachers think about this phenomena, how they interfere when it happens in elementary public schools and what do they expect to study about this theme during teacher training. Six trainees and six public school teachers were interviewed in Recife, Brazil. As results, we identified that the research participants found it difficult to characterize how bullying is present in schools. They consider that this is a relevant issue, even thou they recognize that their teacher education did not address this problem. When questioned about how to interfere, they proposed that dialogue is the best resource and that parents and other authorities must be involved. The study leads to conclude that bullying is recognized as a problem that concerns schools and teachers, but it has not been studied regularly in formal education or in teacher training.
\end{abstract}

Keywords: Bullying, teacher education, elementary education.

\section{¿Profesores saben qué es bullying? Un tema para la formación docente}

\section{Resumen}

La investigación cualitativa enfocó el tema bullying en la formación de profesores y tuvo como objetivo reflexionar sobre las concepciones sobre el fenómeno, sobre lo que consideran medios eficaces de intervención ante casos ocurridos en escuelas públicas de enseñanza fundamental, así como sobre las demandas para la formación docente. Se entrevistó seis profesores en una escuela municipal de Recife y seis estudiantes de licenciatura en la Universidad Federal de Pernambuco. Los resultados identifican que los participantes tuvieron dificultades de definir bullying y de caracterizar su presencia y alcance en la escuela. Además, consideran el tema relevante, a pesar de indicar que está poco presente en los cursos de formación. En cuanto a formas de intervención proponen el diálogo y el envolvimiento de los padres de familia y otras autoridades públicas. Se concluye que el bullying es reconocido como problema que concierne a escuelas y profesores, sin embargo no se constituye un tópico de estudio sistemático en la formación de licenciados.

Palabras Claves: Bullying. Formación de profesores. Enseñanza Fundamental. 


\section{Introdução}

O tema do bullying tem tido presença em manchetes de jornais, principalmente quando ocorrem desfechos trágicos. O termo bullying vem da palavra inglesa bully, que significa valentão e é utilizada de modo geral para dar nome "ao desejo consciente e deliberado de maltratar outra pessoa e colocá-la sob tensão" (Tatum e Herbert, Citados por Pedra \& Fante, 2008). O bullying se caracteriza pela ocorrência de ações agressivas, intencionais, repetitivas e sem motivação aparente que causam dor, angústia ou intimidação. Segundo Fante (2005), o que propicia a ocorrência do bullying é a existência de um desequilíbrio de poder entre o agressor e a vítima, e se deve ao fato de o agredido não conseguir se defender, por não ser tão forte quanto o agressor ou por possuir características psicológicas ou físicas que o tornam alvo de discriminação. Como características do bullying podem-se citar as agressões físicas, insultos, difamação, exclusão, isolamento, roubo de pertences, apelidos, humilhações, intimidações, discriminações, insinuações e ofensas.

As vítimas desse fenômeno podem sofrer danos psíquicos difíceis de reparar, e eventualmente desenvolvem quadros depressivos, apresentam dificuldades em relacionar-se com outras pessoas, passam a ter dificuldades no aprendizado, podendo inclusive assumir a posição de agressores em novas situações de bullying (Lopes Neto, 2005)

Alvos, autores e testemunhas enfrentam consequências físicas e emocionais a curto e longo prazo, as quais podem causar dificuldades acadêmicas, sociais, emocionais e legais. Evidentemente, as crianças e adolescentes não são acometidas de maneira uniforme, mas existe uma relação direta com a frequência, duração e severidade dos atos de bullying.

É importante destacar, como o faz Lopes Neto, que no fenômeno bullying os participantes não se restringem às vítimas e aos agressores, mas também existem as testemunhas, pessoas que não sofrem e não praticam o fenômeno diretamente, mas presenciam quando ele ocorre, porém não fazem nada para ajudar as vítimas a defender-se, pois têm medo de também tornar-se alvo de ataques.

O bullying pode ocorrer em diversos locais, contudo é no ambiente escolar que a incidência desse fenômeno é maior. A esse respeito, Pedra \& Fante, (2008, p. 41) afirmam:

Simplesmente, os que praticam bullying elegem um colega que tenha em seu aspecto físico ou psicológico traços que denunciam ser ele uma presa fácil aos ataques. Portanto o bullying nasce da recusa a uma diferença, da intolerância, do desrespeito ao outro.

Geralmente, quem age como agressor em situações de bullying são pessoas arrogantes, que têm habilidades persuasivas e se divertem ridicularizando e provocando sofrimento em colegas a quem direcionam suas agressões de modo sistemático e aparentemente sem motivo. Essas características se contrapõem às das vítimas, que são usu- almente retraídas e tímidas, têm baixa autoestima e tendem a ser submissas (Pedra \& Fante, 2008).

Devido à grande proporção que esse fenômeno está ganhando na sociedade, e particularmente no ambiente escolar, instaurou-se atualmente uma preocupação quanto à forma de lidar com o assunto. Em debates transmitidos pelos meios de comunicação de massa fica evidente a busca por ações e medidas efetivas que ajudem a combater o bullying. Nesta direção, a escola, que lida diretamente com alunos pré-adolescentes, adolescentes e jovens, torna-se o local onde se concentram as ações de enfrentamento do problema, pois estudos evidenciam que casos de bullying são mais frequentes entre alunos do $6^{\circ}$ ao $9^{\circ}$ ano do Ensino Fundamental (Pedra \& Fante, 2008). Uma justificativa para essa concentração maior é o fato de ser este um período da vida em que os papéis sociais introjetados se manifestam com maior clareza.

Não obstante, é importante frisar que antes de classificar um ato de violência como bullying deve-se analisar o contexto situacional, levando-se em consideração as características individuais das pessoas envolvidas, bem como os contextos familiar e escolar, pois estes núcleos sociais influenciam o comportamento do indivíduo. Nesta direção, vale a seguinte recomendação:

Para prevenir e enfrentar o bullying ou qualquer outro tipo de violência que ocorre no contexto escolar, não se deve partir de receitas prontas e fechadas, pois cada escola possui uma realidade específica, onde são construídas relações diferenciadas entre os seus membros. Sendo assim, o bullying também irá se apresentar de formas diferentes em cada contexto, não devendo, portanto, ser avaliado de modo descontextualizado. (Freire \& Aires, 2012, p. 57)

Se este é um debate que concerne à sociedade como um todo, pois evidencia que as causas e consequências do fenômeno não se circunscrevem apenas a uma esfera intersubjetiva, ocasional ou própria dos processos de desenvolvimento humano, mais particularmente interessa a educadores, tanto os que atuam no campo escolar quanto aqueles em processo de formação profissional.

Apesar de uma discussão mais ampla desenvolvida nos meios de comunicação, e da presença deste tema como parte da formação inicial de pedagogos, identificamos que esta temática tem se constituído num campo ainda incipiente de pesquisa acadêmica. Evidência disto é que, em levantamento sobre os trabalhos apresentados nos últimos cinco anos nas reuniões da Associação Nacional de Pós-Graduação e Pesquisa em Educação (ANPED) ${ }^{1}$ e no Encontro Nacional de Didática e Práticas de Ensino (ENDIPE)2, nenhuma pesquisa apresentada naqueles fóruns de divulga-

\footnotetext{
1 Associação Nacional de Pós-graduação e Pesquisa em Educação (2011). Recuperado: 20 jun. 2011. Disponível: http://www.anped.org. br/

2 Encontro Nacional de Didática e Práticas de Ensino (2010) Recuperado: 20 jun. 2011. Disponível: http://www.fae.ufmg.br/ endipe/programacao.php
} 
ção científica abordava o tema do bullying na formação dos professores.

Em buscas realizadas no site da Associação Brasileira de Psicologia Escolar e Educacional (ABRAPEE) no período de 2007 a 2011 foram encontrados quatro artigos, publicados na Revista Psicologia Escolar e Educacional, que abordavam a violência na escola, e apenas um desses artigos se referia diretamente ao fenômeno do bullying. Segundo esse estudo, que tinha como foco a relação entre bullying, gênero e autoestima,

A interação verificada entre sexo e papéis de bullying em relação à autoestima indica que, no grupo vítimas/ agressores, o sexo masculino apresentou média superior de autoestima em relação ao sexo feminino. Entre as meninas, baixos níveis de autoestima estão relacionados com o papel de vítima/agressor, o que não ocorre entre os meninos. Uma explicação para estes achados pode estar na diferença quanto aos fatores que influenciam a autoestima de meninos e meninas. (Bandeira \& Hutz, 2010, p.136).

Outra fonte pesquisada foi a Associação Nacional de Pesquisa e Pós-Graduação em Psicologia (ANPEPP), que nos cinco últimos anos registrou em seus anais somente uma pesquisa sobre o bullying. Esse estudo dava ênfase às questões afetivas dos adolescentes, concluindo que os professores e os pais devem dialogar com eles, buscando saber como eles se sentem, quais as dificuldades que estão enfrentando, pois assim eles, em ocorrendo o bullying, conseguiriam ajudá-los a lidar de modo mais satisfatório com a situação (Tognetta, 2005).

No XX Encontro de Pesquisa Educacional do Norte e Nordeste (EPENN, 2011) foram encontrados três artigos no grupo de trabalho (GT) de Sociologia da Educação e um artigo no GT Psicologia da Educação que tinham o bullying como tema. Todos se referem a pesquisas empíricas em escolas, com temas que envolvem, por um lado, os tipos de violência identificados (Barbosa, Andrade, Montenegro, \& Costa, 2011; Botelho, 2011), e por outro, a violência escolar na perspectiva do aluno (Ferreira \& Coelho, 2011; Nascimento, Vieira, \& Trindade, 2011). Na ótica de jovens estudantes de escolas públicas entrevistados, as práticas de bullying são

Nocivas ao aluno, prejudiciais ao seu aprendizado e a sua permanência na escola podendo levá-lo ao adoecimento e até mesmo ao suicídio como forma de libertar-se do sofrimento. A intimidação, juntamente com a ameaça, a humilhação a agressão verbal, física e virtual são formas frequentes de ocorrência do bullying na escola (Nascimento e cols., 2011, p. 7).

As discussões em torno da importância de o professor saber mais sobre bullying para intervir em situações de ocorrência do fenômeno também estão presentes no debate acadêmico, porém não há consenso entre os autores a esse respeito, tanto que Iguns defendem a ideia de que não é necessário o professor saber especificamente o conceito de bullying para lidar com ele na sala de aula. Nesta direção, (Santos, 2007) afirma:

Acreditamos que para se combater ou prevenir o bullying na sala de aula não é necessário o conhecimento do professor sobre o conceito de bullying, obviamente que se o professor conhecer o que é o bullying e suas conseqüências tudo será facilitado para se trabalhar a sua prevenção na sala de aula. O bullying, em um contexto geral nada mais é do que uma forma de desrespeito ao próximo, de não aceitação das diferenças e cabe ao professor trabalhar esses conceitos com seus alunos e para isso não é necessário que o professor saiba o que é o bullying. (p.18).

Para fazer essa afirmação, Santos (2007) leva em consideração que os Parâmetros Curriculares Nacionais (PCNs) orientam os professores a trabalharem os conteúdos de ética na sala de aula, o que deveria resultar na redução da prática do bullying.

Em contraposição a essa afirmação, Toro, Neves, \& Rezende (2010, p. 134) afirmam: "Faz-se necessária, portanto, a conscientização a respeito do bullying para que sejam realizadas intervenções criativas e bem contextualizadas, amparadas por relações de confiança".

Assim, neste debate identificamos uma posição segundo a qual se deve dar prioridade à educação para os direitos humanos e uma segundo a qual os professores precisam ser capazes de identificar ocorrências que caracterizam o bullying para que possam intervir de modo mais eficaz diante do problema.

Pautados nessa segunda perspectiva, estudos realizados pela Associação Brasileira Multiprofissional da Proteção à Infância e Adolescência (ABRAPIA) ${ }^{3}$ e pela Plan Brasil $^{4}$ apontam possíveis modos de intervir no ambiente escolar de modo a reverter situações de ocorrência de bullying. Essas organizações fizeram levantamentos de dados que permitiram conhecer as situações de bullying nas relações entre estudantes dentro das escolas. Como decorrência destes estudos, essas organizações criaram programas de redução da violência que visavam alertar e orientar estudantes, pais, gestores e docentes escolares sobre a ocorrência de bullying, as formas de reduzir sua frequência e as graves consequências que pode provocar nas pessoas envolvidas, nas instituições de ensino e no próprio processo de formação e de consolidação da cidadania. Outros estudos destacam que é importante fortalecer ações contra o bullying já existentes nas escolas, considerando-se os contextos locais e suas especificidades.

Esse debate em torno das estratégias de como lidar com o bullying inclui demandas para a formação docente, o que nos motivou a levantar como o tema está sendo tratado

3 A pesquisa foi realizada em 2003 pela ABRAPIA, Organização não governamental idealizada pelo pediatra Lauro Monteiro e fundada no Rio de Janeiro em 1988.

4 Pesquisa realizada em 2009 pela Plan Brasil, uma organização não governamental de origem inglesa ativa há mais de 70 anos. 
pelas instâncias reguladoras da educação nacional e por órgãos representativos de docentes.

Nas buscas realizadas no site do Conselho Nacional de Educação $(\mathrm{CNE})^{5}$ foram encontrados artigos em forma de notícia que tinham o bullying como foco, porém constatamos que este órgão regulador não tem tratado do tema senão com um objetivo meramente informativo. Por sua parte, na página eletrônica da Associação Nacional pela Formação dos Profissionais da Educação (ANFOPE) 6 não foi encontrado nada referente ao tema, mas no site da Confederação Nacional dos Trabalhadores em Educação (CNTE) ${ }^{7}$ foi encontrada uma revista, intitulada Retratos da Escola, que trata da violência. Naquela publicação não encontramos nenhuma menção ao bullying, embora traga artigos que tratam da falta de segurança enfrentada pelos alunos ao irem à escola ou da violência que pode ocorrer dentro da escola.

Em nosso levantamento, não identificamos nesses órgãos representativos de professores (a ANFOPE e a CNTE) e no órgão regulador de políticas nacionais para o ensino e formação docente (o CNE) nenhuma normatização ou alguma pauta de reivindicação para a formação de licenciados que tivesse como foco o bullying.

Ademais, as discussões sobre o bullying não se restringem aos órgãos representativos de professores, pois esta questão é muito mais ampla. Exemplo disso é a proposição de alguns projetos de lei no Senado Federal que dão ênfase ao tratamento do bullying ${ }^{8}$.

O Projeto de Lei $n^{\circ} 228 / 2010$, em tramitação no Senado Federal, versa sobre a inclusão na Lei de Diretrizes e Bases da Educação Nacional (Lei n. ${ }^{\circ}$ 9.394/96) de dispositivos que assegurem a adoção de medidas de prevenção e combate a atos de intimidação e agressão nas escolas. $\mathrm{Na}$ Câmara dos Deputados há sete projetos de lei em tramitação que estabelecem ações com vista a coibir o bullying, entre os quais se destaca o de $n^{\circ} 6.935 / 2010$, que criminaliza tal prática ${ }^{9}$.

Em Pernambuco, foi aprovada a Lei n. ${ }^{\circ} 13.995$, de 22 de dezembro de 2009, que dispõe sobre a inclusão de medidas de conscientização, prevenção, diagnose e combate ao bullying escolar no projeto pedagógico elaborado pelas escolas públicas e privadas de Educação Básica ${ }^{10}$.

5 Conselho Nacional de Educação. (2011). Recuperado: 15 jun. 2011. Disponível: http://www.cnedu.pt/

6 Associação Nacional pela Formação dos Profissionais da Educação. (2011). Recuperado: 17 jun. 2011. Disponível: http:// anfope.spaceblog.com.br/

7 Confederação Nacional dos Trabalhadores em Educação. Recuperado: 20 jun. 2011. Disponível: http://www.cnte.org.br/

8 Portal de notícias do senado. Recuperado:15 abr. 2011. Disponível: http://www.senado.gov.br/noticias/senadoNaMidia/ noticia. $a s p ? n=543293 \& \mathrm{t}=1$

9 Projeto de lei n. 6.935/2010, que busca a inclusão do art. 141A no Código Penal Brasileiro, com a seguinte redação: "Intimidar o indivíduo ou o grupo de indivíduos que de forma agressiva, intencional e repetitiva, por motivo torpe, cause dor, angústia ou sofrimento, ofendendo sua dignidade: Pena - detenção de um mês a seis meses e multa. Recuperado: 28 nov. 2011. Disponível: http://www.cartaforense.com.br/conteudo/artigos/criminalizacao-dobullying-posicao-contraria/9950

10 Lei $n^{\circ} 13.995$, de 22 de dezembro de 2009. Dispõe sobre a
Diante do exposto, entendemos que no âmbito educacional o tema não tem tido prioridade, o que dificulta a tomada de decisões tanto por parte de professores quanto de gestores educacionais para o enfrentamento do fenômeno de forma adequada e ampla.

Diante da constatação de que este tema ainda não ganhou centralidade nas pesquisas no campo educacional nem na formulação de políticas públicas mais abrangentes, entendemos que várias dimensões do fenômeno ainda precisam ser objeto de reflexões e estudos mais sistemáticos.

Neste contexto, o estudo relatado neste artigo teve como objeto investigar quais as demandas formativas de professores já formados ou em processo de formação inicial para lidar com jovens na faixa do segundo segmento do Ensino Fundamental ( $6^{\circ}$ ao $9^{\circ}$ ano) em termos de conhecimentos e maneiras de intervir nas situações de bullying na escola. A pesquisa empírica foi realizada em 2011 numa escola da rede municipal de ensino do Recife e na Universidade Federal de Pernambuco, com estudantes, docentes e coordenadores de cursos de licenciaturas diversas. O relato apresentado neste artigo é um recorte dessa investigação, com ênfase no que foi coletado junto a dois grupos de informantes: os estudantes de cursos de licenciatura e os docentes que atuam no segundo segmento do Ensino Fundamental.

\section{Metodologia}

A pesquisa realizada é de natureza qualitativa e exploratória e utilizou entrevistas como procedimento para coleta de dados, uma vez que esta abordagem favorece uma aproximação da forma como os professores regentes e estudantes de licenciaturas diversas falam sobre suas concepções de bullying e sobre as demandas formativas nessa área. Para Gil (1999), este tipo de estudo visa proporcionar ao pesquisador um maior conhecimento sobre o tema, de modo que esse possa formular problemas mais precisos ou criar hipóteses que possam ser pesquisadas em estudos posteriores. As pesquisas exploratórias visam proporcionar uma visão geral sobre determinado fato, do tipo aproximativo (Gil, 1999, p. 43).

O presente estudo buscou identificar, por meio de levantamento bibliográfico, de análise de documentos oficiais de entidades representativas de professores e de entrevistas com estudantes e com professores licenciados em diversas áreas do conhecimento, quais as demandas formativas para lidar com jovens na faixa do segundo segmento do Ensino Fundamental (11-14 anos) em termos de conhecimentos e maneiras de intervir nas situações de bullying na escola.

inclusão de medidas de conscientização, prevenção, diagnose e combate ao bullying escolar no projeto pedagógico elaborado pelas escolas públicas e privadas de Educação Básica do Estado de Pernambuco e dá outras providências. Palácio do Campo das Princesas. 2009. Recuperado: 28 nov. 2011. Disponível: http:// suelyedh.blogspot.com/2010/06/bullying-lei-ao-enfrentamentoviolencia.html 
A coleta de dados, para a qual foi utilizada entrevista semiestruturada, ${ }^{11}$ envolveu a introdução de questões que não estavam previstas no roteiro inicial, mas surgiram de acordo com o que aconteceu no processo em relação às informações que se desejava obter, proporcionando assim um aprofundamento do tema pesquisado. As entrevistas foram audiogravadas em sistema digital (mp4) e posteriormente transcritas.

As entrevistas com licenciandos foram realizadas na Universidade Federal de Pernambuco (UFPE) ${ }^{12}$, que possui ao todo 86 cursos de graduação distribuídos nos campi do Recife, de Caruaru e de Vitória de Santo Antão. Aquela instituição de ensino superior abriga cursos das mais diversas áreas do conhecimento, dentre os quais vinte e um são de licenciaturas diversas.

Já as entrevistas com professores regentes com formação em diferentes licenciaturas ocorreram em uma escola municipal localizada na Zona Sul do Recife que atendia 787 alunos. A escolha dessa escola como campo de pesquisa deveu-se ao fato de nela ter ocorrido um caso de bullying que ganhou repercussão nacional, por ter tido um desfecho trágico, com agressões físicas contra uma jovem estudante nas imediações da escola ${ }^{13}$. Como decorrência do fato, houve intervenções por parte da Secretaria Municipal de Educação, que realizou uma série de palestras especificamente voltadas para o tema do bullying, envolvendo os professores da escola.

$\mathrm{Na}$ Universidade Federal de Pernambuco (UFPE) foram entrevistados ao todo seis estudantes, distribuídos entre os que cursam licenciatura nas três áreas que organizam o currículo, que são a de ciências exatas (que compreende os cursos de Matemática, Física e química), a de ciências humanas (formada pelos cursos de Letras, História e Geografia) e a de ciências da saúde (cursos de Educação Física e Ciências Biológicas). Dos licenciandos entrevistados, quatro são do sexo masculino e dois do sexo feminino, com idades entre 21 e 26 anos. Os critérios para a escolha dos alunos entrevistados foram eles estarem cursando entre o sétimo e o nono períodos de seus respectivos cursos e terem experiência de estágio em escola. A razão dessa escolha foi a pressuposição de que os acadêmicos talvez já tivessem tratado do tema bullying em sala de aula ou vivenciado algum caso nos estágios em escolas públicas.

$\mathrm{Na}$ escola, também foram entrevistados seis professores, sendo um de cada uma das disciplinas que compõem o currículo do segundo segmento do Ensino Fundamental, o qual inclui as disciplinas de Português, Educação Artística, Matemática, Ciências, História, Geografia e Educação Física. Não foi possível entrevistar a professora de Português, porque ela estava de licença e estava sendo substituída por um estagiário regente. Desses entrevistados, quatro eram do

11 A referida entrevista se encontra anexada ao final deste artigo no apêndice $A$.

12 Entrevistas realizadas em 2011.

13 Aluna é agredida a paulada por não comer merenda escolar em Recife. Recuperado: 20 nov. 2011. Disponível: http://www.paraiba. com.br/2011/05/18/59434-aluna-e-agredida-por-nao-comermerenda-escolar-em-recife-veja-video sexo feminino e dois do sexo masculino, incluídos na faixa etária entre 52 e 64 anos de idade. O critério utilizado para a escolha dos professores que atuam no segundo segmento do Ensino Fundamental a serem entrevistados era que cada um fosse de uma licenciatura diferente (para assim abranger todas as disciplinas curriculares) e que contassem pelo menos cinco anos de atuação na área de ensino. A proposta de entrevistar professores com alguma experiência docente se apoiou na suposição de que professores iniciantes talvez ainda não se tivessem se deparado com o fenômeno bullying em sua prática docente.

\section{Resultados e discussões}

Neste item são apresentados os resultados da pesquisa, os quais foram agrupados nas seguintes categorias: O conceito de bullying e a relevância do tema para os educadores; A abordagem do tema na formação inicial desses profissionais; As formas de intervenção que os docentes consideram mais eficazes. As categorias acima citadas foram elaboradas com os objetivos de verificar o que os estudantes das licenciaturas diversas e os professores do segundo segmento do Ensino Fundamental entendem como demandas para sua formação no tocante à questão do bullying e identificar como estão se preparando para lidar com o assunto e se eles possuem uma formação que favoreça a escolha de intervenções pedagógicas diante do problema.

\section{Conceito de bullying e sua relevância.}

Quando questionados a respeito do conceito de bullying e de sua relevância enquanto fenômeno presente nas escolas, os entrevistados deram respostas que variavam de posicionamentos relativamente superficiais e pouco delimitados até definições mais precisas e próximas do que afirmam os estudiosos da área, particularmente aquela postulada por Fante (2005, p. 28-29), quando afirma:

(...) bullying é um conjunto de atitudes agressivas, intencionais e repetitivas que ocorrem sem motivação evidente, adotado por um ou mais alunos contra outro(s), causando dor, angústia e sofrimento. Insultos, intimidações, apelidos cruéis, gozações que magoam profundamente, acusações injustas, atuação de grupos que hostilizam, ridicularizam e infernizam a vida de outros alunos, levandoos à exclusão, além de danos físicos, morais e materiais, são algumas manifestações do comportamento bullying.

Os entrevistados, tanto os estudantes de licenciatura quanto os professores, quando definem o conceito de bullying, restringem-no a apelidos ou a algumas características isoladas do fenômeno, como, por exemplo, a provocação, a discriminação e zombaria, a perseguição, piadas, preconceito, agressões e brincadeiras grosseiras. Em alguns 
casos, os entrevistados associavam o bullying à violência, sem maior discriminação do fenômeno.

Desse modo, consideramos que eles têm um entendimento fragmentado e pouco abrangente sobre o conceito de bullying, que se caracteriza como um conjunto de ocorrências articuladas, e não como atos isolados de agressão. Não obstante, um professor definiu o significado do termo bullying de um modo mais amplo: "É uma palavra inglesa. Denegrir a reputação de alguém, diminuir a personalidade, através de crítica, de abuso. Essa palavra significa valentão, se aproveitar dos menos favorecidos fisicamente como um gordinho, baixinho".

Pelo menos um dos licenciandos conceituou o bullying de modo mais fundamentado ao falar que o fenômeno significa "desigualdade de poder, caso de saúde pública, acarreta danos psíquicos, agressões".

Em suas respostas, tanto os professores como os licenciandos passaram a impressão de que ainda não se haviam apropriado totalmente do tema, por isso, ao serem questionados sobre a relevância do bullying, também deram respostas vagas.

Destacamos aqui duas falas contrastantes, a de um professor e a de um aluno de licenciatura. O primeiro deu uma explicação religiosa e moral para a questão, deixando claro que não vê a possibilidade de abordagem do bullying no ambiente escolar, pois, segundo ele, "o bullying não é um assunto que a escola ou a sociedade irá resolver, pois só Deus quando chegar no dia do juízo poderá resolver esse e outros problemas que afetam a humanidade". Para esse participante da pesquisa, o bullying é um problema que a sociedade e a escola não poderão resolver e que, por isso mesmo, foge às possibilidades de uma intervenção pedagógica eficaz. Em contraste, um estudante de licenciatura afirmou: "É um caso de saúde pública. Garantir os direitos do cidadão e da coletividade. O bullying é um fenômeno decisório de influência enorme do processo ensino-aprendizagem do aluno. Deve-se atentar para os prejuízos psíquicos da pessoa".

Ao situar a questão como um fenômeno mais coletivo (de saúde pública) e capaz de intervir no processo de aprendizagem, relega tanto aos profissionais da saúde quanto aos de ensino a responsabilidade de conhecer e intervir no fenômeno. Nessa direção Lopes Neto (2005) afirma: "As instituições de saúde e educação, assim como seus profissionais, devem reconhecer a extensão e o impacto gerado pela prática de bullying entre estudantes e desenvolver medidas para reduzi-la rapidamente" (p. 170).

Nesta mesma direção, o estudo de Freire e Aires (2012), citado anteriormente, recomenda não agir perante o bullying com receitas prontas, mas atentar para a questão de que o fenômeno deve ser avaliado sempre em seu contexto social, com suas devidas particularidades, as quais envolvem tanto a família quanto a escola. Além disso, num sentido mais amplo, os enfrentamentos que ocorrem nas situações de bullying podem evidenciar valores hegemônicos na sociedade que são reproduzidos numa instância intersubjetiva, não se caracterizando exclusivamente como uma questão de natureza psicológica.

Ao analisar a respostas dadas sobre o conceito de bullying nota-se que todos os entrevistados, apesar de afirmarem já terem ouvido falar sobre o bullying, ainda não tinham um conhecimento amplo sobre o assunto e por isso acabavam resumindo o bullying a agressões verbais ou físicas, perseguição e apelidos, ou simplesmente não emitiam opinião sobre o tema, por não saberem muita coisa a respeito ou por não quererem falar sobre o assunto. Nesta direção, podemos indicar que, à semelhança de outros problemas, como as discriminações de gênero e raça/etnia, o "silenciamento" acaba favorecendo uma omissão diante das vítimas e dos agressores, e a falta de informações parece favorecer posturas imobilistas diante das ocorrências na escola.

\section{O bullying na formação docente}

Dos seis entrevistados, apenas um professor afirmou ter estudado sobre o bullying durante a sua formação inicial, por meio de debates nas disciplinas de Psicologia Social e Prática de Ensino. Uma professora afirmou ter assistido a aulas em que "falavam sobre discriminação", e os demais professores afirmaram não ter sido abordado o assunto em nenhuma momento de sua formação inicial para a docência. Como esse grupo já atuava na profissão havia mais de vinte anos, inferimos que sua formação inicial se dera num período em que a discussão sobre o bullying não se constituía num tema que fizesse parte do repertório de conteúdos tratados nos cursos de graduação de licenciandos.

Por sua vez, os alunos de cursos de licenciatura entrevistados afirmaram ter sido tratado o assunto em disciplinas como Psicologia da Educação (quando se discute o desenvolvimento socioafetivo), Prática de Ensino e Didática. Somente um aluno disse não ter estudado esse assunto em nenhuma disciplina. Os demais haviam estudado o tema nas disciplinas de Psicologia da Educação, Didática, Prática de Ensino, Fundamentos da Educação, Sociologia, Filosofia, Direito à Cidadania. $\mathrm{A}$ incidência maior de referências ao estudo do tema ocorreu na disciplina Psicologia.

Em relação aos conteúdos tratados, dois dos professores que haviam estudado o bullying em sua formação inicial disseram que o assunto fora abordado em forma de debates gerais em sala de aula. Desses dois educadores que haviam estudado o assunto, um afirmou não saber especificar o conteúdo e uma professora disse que o assunto fora tratado como discriminação, pois no tempo em que ela se formara o termo bullying não era conhecido.

Por sua vez, quando questionados sobre que conteúdos envolviam o tema do bullying nas disciplinas acadêmicas, quatro alunos de licenciatura falaram que o assunto foi estudado em forma de debates, seminários ou discussões. Um estudante disse não ter estudado em nenhuma disciplina. Vale destacar a fala de um dos educandos, que explicou como a abordagem do bullying era feita nas disciplinas: "Elas (as disciplinas) têm em comum ressaltar o caráter 
de alta relevância a observância do fenômeno no ambiente escolar, minuciando (sic) os possiveis desdobramentos caso ocorra, bem como quais seriam as posturas; medidas de intervenção e prevenção".

Desse depoimento destacamos o fato de que a abordagem do tema na formação inicial do estudante não se restringiu à dimensão cognitiva da questão, incidindo também na esfera atitudinal, o que reforça a ideia defendida por estudiosos da área de formação docente de que a identidade profissional não se constitui apenas de aspectos técnicos, mas envolve a pessoa do educador como um todo (Candau, 1997; Nóvoa, 1992; Sacristán, 1993;).

Os licenciandos que afirmaram ter sido tratado o bullying através de discussões e debates afirmaram que o assunto surgira a partir do interesse deles mesmos, devido à vivência deles nos estágios, e não porque os professores tivessem o bullying como conteúdo programático já previsto para ser tratado em sala de aula. Se, por um lado, esses depoimentos evidenciam que a abordagem do tema foi ocasional e assistemática, por outro demonstram que a formação de professores, mesmo na etapa inicial, precisa considerar a experiência docente e os problemas que emergem do cotidiano escolar.

\section{Formas de intervenção}

Ao serem perguntados sobre suas intervenções diante da ocorrência de bullying na sala de aula, os professores entrevistados afirmaram que sua primeira reação é observar se as agressões são persistentes e em seguida dialogar com os envolvidos, buscando mostrar-Ihes que estão agindo de modo errado. Se a conversa não surtir efeito, eles encaminham o caso para a direção da escola ou para outras autoridades, por exemplo, para o conselho tutelar. Sobre isso uma professora falou: "Observando a forma de agressividade a partir daí favorecer o encaminhamento para cada caso, por exemplo, o caso de chamar os pais, o caso de conversar, tem o caso de chamar a polícia, o conselho tutelar. Tem formas e até graus de agressividade do bullying".

Um professor disse: "Converso, explico por que não pode agredir, e se possível, eu repreendo mesmo de voz grossa". Por sua vez, uma das professoras afirmou: "Intervenho todos os dias, todos os dias dizendo o que é bullying, quando eu vejo alguma brincadeira para menosprezar o outro, sempre reclamo. Nós temos um menino que ele é cego e mudo e eles chamavam ceguinho, ceguinho. Eu disse: por que ceguinho? Ele tem nome, o nome dele é Daniel ${ }^{14}$ e o nome dele é até bonito. Então eu chamei os pais dos meninos que o chamavam de ceguinho, conversei com os pais e os pais "acocharam" de um lado e eu "acochei" do outro e hoje os meninos não chamam mais ele de ceguinho".

Uma professora respondeu: "Conversando com os alunos, esclarecendo". Por fim, outra professora afirmou: "Dialogo com o grupo ou particularmente com algum aluno

\footnotetext{
14 Nome fictício.
}

orientando o que não deve fazer, como ele se sentiria... Chamando à confiança. Como é que ele se sentiria se fosse com ele, orientando a aceitar e valorizar o colega. Quando não tem solução, a gente parte pra família ou vem à coordenação, à direção, entendeu? Devemos ter palestras, cursos que abordem o tema".

Deste modo, identificamos que os professores assumem uma postura de reação somente diante do fenômeno, mas só reagem quando percebem que o bullying está acontecendo. Essa postura dos professores indica que, apesar de a escola ter em seu histórico um caso de bullying diagnosticado e, devido a esse fato, a Secretaria de Educação ter realizado na escola palestras sobre o tema, os docentes sentem carência de apoio no enfrentamento do problema, a ponto de sugerirem que a escola propicie mais debates, palestras e cursos sobre o tema. Em nenhum momento das entrevistas os professores se referiram à existência, na escola, de algum programa ou iniciativa de ação contínua que objetivasse a prevenção e o enfrentamento do bullying, além das palestras pontuais que foram oferecidas pela Secretaria de Educação, as quais parecem não ter sido suficientes para instrumentalizá-los para uma intervenção mais eficaz. Uma professora chegou a expressar o sentimento de que não estava preparada para intervir nesses casos ao afirmar: " $A$ gente precisava de mais capacitação, apesar de que a gente teve uma muito boa aqui".

Por sua vez, quando questionados sobre as maneiras de intervenção diante do fenômeno, os estudantes de licenciaturas diversas tiveram respostas bem semelhantes às dos professores experientes. Todos afirmaram agir (nas situações de estágio) através de observações e conversas, e quando percebiam que essas conversas eram insuficientes para reverter a situação, levavam o caso para a direção da escola.

Um dos licenciandos especifica qual o modo como pretende agir diante de possíveis casos de bullying: "Primeiramente repreenderia o causador do bullying e depois iria tentar conscientizá-lo juntamente com a turma de que aquilo é errado. O professor deve saber primeiramente os sinais ou indicadores do bullying para poder intervir caso precise, como também seus efeitos".

Outro aluno de licenciatura disse: "Conversava e punia; chamava pai e mãe". Por sua vez, um terceiro licenciando respondeu: "Converso com os alunos pra eles entenderem que aquilo ali não é o certo. Acho que deve haver cursos de capacitação". Por sua vez, um dos alunos de licenciatura disse: "Interviria através de diálogos com os envolvidos". Outro estudante propôs uma intervenção mais pontual, com o acionamento de profissionais do campo da Psicologia: "A bem da verdade, a intervenção seria segmentada em etapas. Reconhecido o caráter intrínseco do fenômeno da desigualdade de poder, encetaria esforços no sentido da conversa com as partes, defendendo a vítima, na tentativa de equilíbrio na relação; no entanto, como sabido, devido ao aspecto reprodutor o agressor, pode ter sido uma vítima, então é necessário investigar esses aparentes pormenores, para intervir com maior propriedade. Segundo: após intervir 
no sentido de cessar com os constrangimentos e violência simbólica própria do fenômeno, na busca de um equilíbrio de forças, alçaria a possibilidade de, após uma conversa com as partes, de um acompanhamento psicológico, haja vista os possiveis e prováveis traumas".

Desse modo, todos falaram que tratam (ou tratariam) o bullying através de diálogos com os participantes do fenômeno ou com autoridades (pais, diretores das escolas) Quando o caso não é resolvido pela escola ou pelos pais, alguns sugerem acionar a polícia ou o conselho tutelar.

Das propostas de intervenção apresentadas podemos inferir que tanto professores experientes quanto estudantes de licenciatura entendem que o bullying é um fenômeno que deve ser resolvido mediante o estabelecimento de uma relação de autoridade - de professor, de pai/ mãe, de diretor da escola, de polícia, de conselheiro tutelar. A autoridade, nesses casos, instaura-se mais pelo diálogo e pela repreensão verbal, e somente em casos mais extremos, com medidas repressivas. Nas falas aparecem tanto propostas de intervenção mais pontual, numa abordagem direta dos agressores, quanto formas de envolvimento do grupo/classe. Em ambos os casos, a estratégia central é "dar lição", ou seja, o educador concentrar-se na capacidade argumentativa, sem que outros modos de envolvimento dos estudantes sejam apresentados.

Podemos identificar limites no modelo proposto pelos participantes da pesquisa, pois este teria como resultado "a imposição heterônoma de valores e normas" (Puig, 1988, p.15), não contribuindo para a construção de relações que tenham como base o respeito mútuo, a reciprocidade, a cooperação e o juízo moral autônomo (Araújo, 1999, p.106).

Além disso, os professores circunscrevem sua intervenção ao campo da admoestação, com apelo à autoridade própria ou de outros. Nesta direção, entendem que a questão pode ser resolvida através do convencimento ou da coerção; porém estudos em educação mora indicam que problemas que envolvem preconceitos e valores demandam estratégias que incidam não somente sobre os aspectos cognitivos, mas que ajudem na construção de novas sociabilidades e na mudança de atitudes (La Taille, 1999; Puig, 1988). Desse modo, parecem reproduzir com os estudantes na escola o modelo presente em seus processos de formação docente, ou seja, tratam a questão apenas no âmbito do debate, da informação, sem considerar aspectos de natureza mais socioafetiva. Mesmo o estudante que mencionou um possível apoio psicológico, não formulou sua proposta em termos mais amplos, mas fundamentou-a num atendimento individualizado e descontextualizado.

\section{Considerações finais}

O estudo que serviu de referência para este artigo (Silva \& Rosa, 2011) evidencia, à semelhança do que é defendido também por outros autores, como Toro e cols. (2010), que os educadores sabem pouco sobre o fenômeno do bullying e que isso tem repercussões nos modos de eles planejarem e realizarem suas intervenções pedagógicas neste campo. Evidencia, ainda, que o tema é pouco tratado, tanto nos processos de formação inicial quanto nos programas de formação continuada de professores e de outros profissionais da educação, como gestores e coordenadores pedagógicos, por exemplo. Por fim, os dados coletados também chamam a atenção para lacunas nos procedimentos didáticos adotados nos processos formativos dos educadores.

Mesmo dentro dos limites de um estudo exploratório, podemos afirmar que o conjunto dos depoimentos coletados junto a professores e estudantes de licenciatura apontou a necessidade de rever os programas de formação inicial e continuada de professores para que estes atuem de modo mais eficaz diante de demandas do cotidiano escolar, como é o caso do bullying. Também indica que a realização pontual de debates ou de palestras é insuficiente para que s professores tenham melhores condições de intervir diante da ocorrência de bullying na escola.

O que os professores devem saber sobre bullying não precisarem esperar que ele ocorra para então reagirem? Como podem organizar uma intervenção que seja de fato pedagógica? Que outras referências podem compor essa intervenção além do apelo à autoridade ou a um eventual sentimento de culpa por parte do agressor? Que aportes a Psicologia Educacional pode trazer para a formação docente neste campo? Essas são questões que emergem a partir do estudo aqui relatado e que certamente demandam novas investigações que contribuam para uma revisão dos modelos adotados nas instituições formadoras, como é o caso das universidades. Como nos lembra Nóvoa (1992),

Estar em formação implica um investimento pessoal, um trabalho livre e criativo sobre os percursos e os projetos próprios, com vista à construção de uma identidade, que é também uma identidade profissional (p. 25).

Para finalizar, destacamos aqui a resposta do professor que propôs uma postura religiosa e determinista em relação ao bullying: a de que "só Deus poderá resolver esse problema quando chegar o juízo final". Esse modo de compreender o fenômeno indica que o desafio da formação docente no que tange a essa problemática exige uma abordagem que supere uma perspectiva meramente informativa ou cognitivista da questão, já que a forma de compreender o bullying pode envolver atitudes e sentimentos que não se sustentam apenas na racionalidade. Essa reflexão nos leva também a questionar a principal estratégia de intervenção proposta pelo grupo de professores, já que aquela é pautada, basicamente, por um modelo racional, que não considera as dimensões atitudinal e afetiva na abordagem do fenômeno.

Uma boa alternativa, já formulada e experimentada por organizações da sociedade civil, é incluir no currículo escolar a abordagem do problema bullying através da discussão de textos e de simulações, visando sensibilizar os alunos e alertá-los para que não sejam obrigados a sofrer em silêncio. 
O debate sobre o bullying e suas formas de intervenção, uma vez presente nos espaços formativos, tanto na formação inicial quanto na continuada, pode contribuir, enfim, para que se construa outro tipo de sociabilidade no espaço escolar, pautado por valores de solidariedade e de convivência respeitosa com as diferenças.

\section{Referências}

Araújo, U. F. de. (1999). O ambiente escolar e o desenvolvimento do juízo moral infantil. Em L. de Macedo (Org.), Cinco estudos de educação moral (pp. 105-136). São Paulo: Casa do Psicólogo.

Bandeira, C. de M., \& Hutz, C. S. (2010). As implicações do bullying na autoestima de adolescentes. Revista Brasileira de Psicologia Escolar e Educacional, 14(1), 131-138. Recuperado: 01 nov 2011. Disponível: http://abrapee.files.wordpress.com/2012/02/14-1.pdf

Barbosa, R. C., Andrade, V. G. de, Montenegro, F. de S., \& Costa, E. M. D. (2011). Conviver sem bullying: pelo direito de estudar em paz". Uma experiência de combate à violência e ao bullying no colégio agrícola Vidal de Negreiros - CAVN. Trabalho apresentado no XX Encontro de Pesquisa Educacional do Norte e Nordeste. Amazonas: UFAM.

Botelho, C. de S., (2011). Trajetórias sociais e construção das discursividades no contexto escolar: um estudo sobre o fenômeno bullying. Trabalho apresentado no XX Encontro de Pesquisa Educacional do Norte e Nordeste. Amazonas: UFAM.

Candau, V. M. (Org.). (1997). Magistério: construção cotidiana. Petrópolis, RJ: Vozes.

Fante, C., (2005). Fenômeno Bullying: Como prevenir a violência nas escolas e educar para a paz (2a ed). Campinas, SP: Veros Editora.

Ferreira, E. M. B., \& Coelho, S. C. R. (2011). Faces e disfarces da violência no ambiente escolar: marcas deixadas na alma de alunos e professores. Trabalho apresentado no XX Encontro de Pesquisa Educacional do Norte e Nordeste. Amazonas: UFAM.

Freire, A. N., \& Aires, J. S. (2012). A contribuição da psicologia escolar na prevenção e no enfrentamento do Bullying. Revista Psicologia. Escolar e Educional, 16(1). Recuperado: 29 abr de 2013. Disponível: http://www.scielo.br/scielo.php?script=sci_artte xt\&pid=\$1413-85572012000100006

Gil, A. C. (1999). Métodos e técnicas de pesquisa social. São Paulo: Atlas.

La Taille, Y. (1996). A educação moral : Kant e Piaget. Em L. De Macedo (Org.), Cinco estudos de educação moral (pp. 37-104). São Paulo: Casa do psicólogo.

Lei n. 9.394, de 20 de dezembro de 1996. (1996, 23 de dezembro). Estabelece as Diretrizes e Bases da Educação Nacional. Diário
Oficial da União, seção 1.

Lei $n^{\circ}$ 13.995, de 22 de dezembro de 2009. (2009). Dispõe sobre a inclusão de medidas de conscientização, prevenção, diagnose e combate ao bullying escolar no projeto pedagógico elaborado pelas escolas públicas e privadas de Educação Básica do Estado de Pernambuco e dá outras providências. Recife: Palácio do Campo das Princesas. Recuperado: 28 nov. 2011. Disponível: http:// suelyedh.blogspot.com/2010/06/bullying-lei-ao-enfrentamentoviolencia.html

Lopes Neto, N. A. A. (2005). Bullying - comportamento agressivo entre estudantes. Jornal de Pediatria, 81(5), supl.

Nascimento, I. P., Vieira, A. S., \& Trindade, M., (2011, agosto). Quero me livrar de você: as representações sociais de jovens de escolas públicas sobre o bullying. Trabalho apresentado no XX Encontro de Pesquisa Educacional do Norte e Nordeste. Amazonas: UFAM.

Nóvoa, A. (Org.). (1992). Vidas de professores. Lisboa: Porto Editora.

Pedra, J. A., \& Fante, C. (2008). Bullying escolar: perguntas e respostas. Porto Alegre: Artmed.

Projeto de lei n. 6.935/2010. (2010). Propõe a inclusão do art. 141A no Código Penal Brasileiro, com a seguinte redação: "Intimidar o indivíduo ou o grupo de indivíduos que de forma agressiva, intencional e repetitiva, por motivo torpe, cause dor, angústia ou sofrimento, ofendendo sua dignidade: Pena - detenção de um mês a seis meses e multa". Recuperado: 28 nov 2011. Disponível: http://www.cartaforense.com.br/conteudo/artigos/criminalizacaodo-bullying-posicao-contraria/9950

Puig, J. M. (1988). Ética e valores: métodos para um ensino transversal. São Paulo: Casa do Psicólogo.

Sacristán, J. G. (1992). Consciência e ação sobre a prática como libertação profissional dos professores. Em A. Nóvoa (Org.), Profissão professor (pp. 63-91). Lisboa: Porto Editora.

Santos, L. P. R. dos. (2007). O papel do professor diante do bullying na sala de aula. Bauru, SP: UNESP. Recuperado: 14 abr 2011. Disponível: http://www.fc.unesp.br/upload/pedagogia/TCC $\% 20$ Luciana\%20Pavan\%20\%20Final.pdf

Silva, E. N., \& Rosa, E. C. (2011). Bullying na formação docente?. Trabalho de Conclusão de Curso, Universidade Federal de Pernambuco, Recife-PE.

Tognetta, L. R. P., \& Vinha, T. P. (2008). Estamos em conflito, eu comigo e com você: uma reflexão sobre o bullying e suas causas afetivas. Em J. L. Cunha, L. S. C. Dani (Orgs.), Escola, conflitos e violências. Santa Maria, RS: Editora da UFSM. Recuperado: 14 abr 2011. Disponível: http://www.mp.sp.gov.br/portal/page/portal/ Educacao/Doutrina/Bullying\%20Estamos\%20em\%20conflito.pdf

Toro, G. V. R, Neves, A. S., \& Rezende, P. C. M. (2010). Bullying, 
o exercício da violência no contexto escolar: reflexões sobre um sintoma social. Revista psicologia: Teoria e Prática, 12(1), 123137. Recuperado: 30 abr 2011. Disponível: http://redalyc.uaemex. $\mathrm{mx} /$ redalyc/pdf/1938/193814418011.pdf

\section{APÊNDICE A}

\section{Entrevistas}

\section{- Roteiro de entrevistas bullying estudantes das licenciaturas diversas.}

Dados pessoais:

Nome:

Idade:

Sexo:

1. Qual o seu curso?

2. Em que período do curso você está?

3. Já atuou como professor/estagiário em alguma escola? Pública ou privada? Quanto tempo?

4. Você sabe o que é bullying?

5. Quais os sinais ou indicadores levam a identificar o bullying?

6. Você acha o tema relevante, por quê?

7. Durante o seu curso você já ouviu falar sobre bullying?

8. Em que disciplinas você viu o tema?

9. De que forma era trabalhado o bullying?

10. Você acha que estaria preparado para fazer intervenções se houvesse casos de bullying no seu ambiente de trabalho?

11. De que forma você interviria?

12. O que você acha que professores precisam saber sobre bullying?

\section{Roteiro de entrevistas bullying professores formados.}

Nome:

Idade:

Sexo:

1. Você é professor de que disciplina?

2. Há quantos anos leciona?

3. Você sabe o que é bullying?

4. Quais os sinais ou indicadores levam a identificar o bullying?

5. Você acha o tema relevante, por quê?

6. Durante sua formação você teve disciplinas que falavam sobre o bullying?

7. Quais disciplinas?

8. De que forma era trabalhado o bullying nessas disciplinas?

9. Você fez capacitações depois do seu curso que traziam o tema bullying e suas formas de intervenções?

10. Você se sente preparado para intervir em casos de bullying?

11. De que forma você intervém/interviria?

12. O que você acha que professores precisam saber sobre bullying? 